\title{
Comparison of maltose and acarbose as inhibitors of maltase-glucoamylase activity in assaying acid $\alpha$-glucosidase activity in dried blood spots for the diagnosis of infantile Pompe disease
}

Haoyue Zhang, PhD ${ }^{1}$, Helmut Kallwass, $P h D^{2}$, Sarah P. Young, $P h D^{1}$, Cortney Carr, $B S^{2}$, Jian Dai, $B S^{1}$, Priya S. Kishnani, $M D^{1}$, David S. Millington, $P h D^{1}$, Joan Keutzer, $P h D^{2}$, Yuan-Tsong Chen, $M D, P h D^{1}$, and Deeksha Bali, $P h D^{1}$

\begin{abstract}
Purpose: The study's purpose was to compare acarbose and maltose as inhibitors of maltase-glucoamylase activity for determining acid $\alpha$-glucosidase activity in dried blood spot specimens for early identification of patients with infantile Pompe disease, a severe form of acid $\alpha$-glucosidase deficiency. Methods: Acid $\alpha$-glucosidase activities in dried blood spot extracts were determined fluorometrically using the artificial substrate 4-methylumbelliferyl- $\alpha$-D-pyranoside. Acarbose or maltose was used to inhibit maltase-glucoamylase, an enzyme present in polymorphonuclear neutrophils that contributes to the total $\alpha$-glucosidase activity at acidic $\mathrm{pH}$. Results: Complete discrimination between patients with proven infantile Pompe disease $(n=20)$, obligate heterozygotes $(n=16)$, and controls ( $n=150$ ) was achieved using $8 \mu \mathrm{mol} / \mathrm{L}$ acarbose as the inhibitor. Higher acarbose concentration (80 $\mu \mathrm{mol} / \mathrm{L}$ ) did not improve the assay. By using $4 \mathrm{mM}$ maltose as the inhibitor, heterozygotes and patients were not completely separated. The results using acarbose compared well with those using the skin fibroblast assay in the same group of patients with proven infantile Pompe disease. Conclusion: Acid $\alpha$-glucosidase activity measurements in dried blood spot extracts can reliably detect infantile Pompe disease in patients. The convenience of collecting and shipping dried blood specimens plus rapid turnaround time makes this assay an attractive alternative to established methods. Genet Med 2006:8(5):302-306.
\end{abstract}

Key Words: Pompe disease, diagnosis, alpha-glucosidase, enzyme assay, dried blood spots

Glycogen storage disease type II, also known as Pompe disease or acid maltase deficiency, is caused by a deficiency or defect in the lysosomal enzyme acid $\alpha$-glucosidase (GAA; EC 3.2.1.20 $)^{1}$ resulting in the lysosomal storage of glycogen. The clinical presentation of Pompe disease is variable with respect to the age of onset, extent and type of organ involvement, and rate of progression. Classic infantile Pompe disease manifests within the first few months of life with hypertrophic cardiomyopathy, hypotonia, a rapidly progressive skeletal myopathy, and feeding and respiratory difficulties. Death usually occurs by the first year of age as the result of cardiorespiratory failure..$^{2,3}$ Late-onset Pompe disease (juvenile and adult types) is characterized by a lack of severe cardiac involvement and a less severe short-term prognosis. Symptoms may start at any age and are related to progressive dysfunction of skeletal mus-

From the ${ }^{I}$ Division of Medical Genetics, Department of Pediatrics, Duke University Medical Center, Durham, NC; ${ }^{2}$ Genzyme Corporation, Cambridge, Mass.

Deeksha S. Bali, PhD, Biochemical Genetics Lab., DUMC, 99, T.W. Alexander Drive, Research Triangle Park, P.O. Box 14991, NC 27709.

Submitted for publication January 9, 2006.

Accepted for publication February 28, 2006.

DOI: 10.1097/01.gim.0000217781.66786.9b cles. Respiratory failure is the cause of significant morbidity and mortality in this form of the disease. The age of death varies from early childhood to late adulthood, depending on the rate of disease progression and the extent of respiratory muscle involvement.

Pompe disease is one of a number of lysosomal storage disorders for which enzyme replacement therapy (ERT) has been developed. ${ }^{4-8}$ There is evidence to suggest that the severity of disease involvement, especially in skeletal muscle tissue, at the start of ERT has a major impact on the response of these tissues to ERT. ${ }^{4-8}$ Therefore it is of the utmost importance to identify patients and initiate treatment as early as possible.

Confirmation of the clinical diagnosis of Pompe disease is established by the virtual absence (infantile-onset) or markedly reduced (late-onset) GAA activity in muscle biopsies, cultured skin fibroblasts or purified lymphocytes, and lymphoid cell lines. Acid $\alpha$-glucosidase hydrolyzes $\alpha 1-4$ and $\alpha 1-6$ bonds in glucose polymers and has an optimum activity between $\mathrm{pH}$ 3.7 and 4.5 , depending on the substrate. ${ }^{9,10}$ In a typical assay, GAA activity is measured at an acidic pH (4.0 or 4.3) and compared with neutral glucosidase activity at $\mathrm{pH} 7.0$ using maltose, glycogen, or the fluorescent synthetic substrate 4-methylumbelliferyl- $\alpha$-D-glucopyranoside (4-MUG) as substrates. Al- 
though the current gold standard is to measure GAA activity in skin fibroblasts or a muscle biopsy, both have limitations as confirmatory tests. Skin fibroblast cultures usually take 3 to 4 weeks to grow to confluency thus delaying the crucial diagnosis of Pompe disease, and muscle tissue, although able to render a shorter turnaround time, is intrusive and exposes patients to significant risk from anesthesia during biopsy. ${ }^{1,3}$ Diagnosis by molecular techniques that identify both disease-causing alleles in the GAA gene is significantly more time-consuming because of the size of the gene ( $20 \mathrm{~kb}, 20$ exons) and the underlying allelic heterogeneity in Pompe disease. None of these methods can be used for newborn screening, which represents the most promising avenue for early diagnosis and effective treatment. ${ }^{11}$

Recently, several enzymatic methods have been described that measure GAA activity in dried blood spots (DBSs) and have been proposed for newborn screening for Pompe disease. ${ }^{12-15}$ DBS extracts contain a polymorphonuclear neutrophil-derived $\alpha$-glucosidase (maltase-glucoamylase, MGA) that interferes with GAA activity measurement at acidic $\mathrm{pH} .{ }^{1,16}$ Isolation of GAA from DBS extracts by immunocapture ${ }^{12}$ or competitive inhibition of MGA activity using maltose or acarbose ${ }^{13,14}$ has been used to remove this interfering activity. Acarbose was used in combination with a novel synthetic lipidated substrate, the enzymatic cleavage product of which was quantified by stable isotope dilution-tandem mass spectrometry. ${ }^{14}$

The purpose of the current study was to evaluate the effectiveness of a straightforward fluorometric assay for GAA activity measurements in DBS extracts to detect infantile-onset Pompe disease in patients, using 4-MUG as the substrate and comparing maltose with acarbose as inhibitors of MGA. The study was performed on the largest group of known affected patients, obligate heterozygotes, and controls accumulated to our knowledge thus far. The effectiveness of these assays for identifying patients with late-onset Pompe disease has been evaluated in a different study and will be described elsewhere. GAA assay in blood on filter paper (DBS) that can be collected by the heel- or finger-stick method and conveniently shipped from locations remote from the analytic center is poised to become a reliable, relatively noninvasive, sensitive, and specific assay with the further advantage of a fast turnaround time. This also has the potential for application to newborn screening.

\section{MATERIALS}

4-Methylumbelliferone (4-MU) and dimethylsulfoxide were obtained from Sigma Chemical Co. (St. Louis, Mo); acarbose from Toronto Research Chemicals, Inc. (Toronto, Canada); maltose monohydrate from EMD Science Inc. (Gibbstown, NJ); 4-methylumbelliferyl- $\alpha$-D-glucopyranoside (4-MUG); and other chemicals from EM Science (San Diego, Calif). Black 96-well microtiter plates and plate sealers were obtained from Corning Incorporated (Corning, NY).

We prepared $70 \mathrm{mmol} / \mathrm{L}$ 4-MUG stock substrate and 25 $\mathrm{mmol} / \mathrm{L} 4-\mathrm{MU}$ stock calibrant solutions in dimethylsulfoxide; $1.4 \mathrm{mmol} / \mathrm{L} 4-\mathrm{MUG}$ in $40 \mathrm{mmol} / \mathrm{L}$ sodium acetate buffer at $\mathrm{pH}$ 3.8 (acidic substrate) and pH 7.0 (neutral substrate) were used as the substrates for acid and neutral $\alpha$-glucosidase activities, respectively. Solutions of maltose monohydrate $(40 \mathrm{mmol} / \mathrm{L})$ and acarbose $(80 \mu \mathrm{mol} / \mathrm{L}$ and $800 \mu \mathrm{mol} / \mathrm{L})$ were prepared in deionized water; $150 \mathrm{mmol} / \mathrm{L}$ EDTA at $\mathrm{pH} 11.4$ was used as the stop buffer.

\section{Blood spot collection}

DBSs were obtained using the standard heel-stick procedure for collecting newborn screening specimens or the drop-wise addition of $60 \mu \mathrm{L}$ of whole blood collected in EDTA-lined tubes onto filter paper grade 903 cards (Schleicher and Schuell Bioscience, Keene, NH). DBS cards were dried in a horizontal position at room temperature for 5 or more hours and stored at $-20^{\circ} \mathrm{C}$ or below in sealed bags in the presence of a desiccant. Samples from patients and heterozygotes were obtained with consent under protocols approved by the institutional review boards at the participating sites.

\section{Control samples}

Control specimens consisted of 55 blinded blood spot samples obtained from individuals being evaluated for defects of fatty acid oxidation and organic acidemias in the Biochemical Genetics Laboratory, Division of Medical Genetics, Duke University Medical Center. In addition, 150 anonymous samples drawn from healthy adults were obtained from a commercial source (ProMedDx LLC, Norton, Mass). These healthy adult control samples were used for the inhibition studies with 8 $\mu \mathrm{mol} / \mathrm{L}$ acarbose. For the $4 \mathrm{mmol} / \mathrm{L}$ maltose inhibition studies, 110 control samples were used ( 55 patient controls plus 55 of the anonymized normal adult controls). Replicates of a DBS made from the same control specimen were used as a quality control.

\section{Patient samples}

De-identified samples were obtained from patients $(n=20)$ with clinically and enzymatically confirmed infantile-onset Pompe disease. GAA activity measured in cultured skin fibroblasts and/or muscle biopsy was less than $1 \%$ of the normal control mean. Heterozygote samples were obtained from biologic parents of patients with a confirmed diagnosis of infantile Pompe disease (16 blinded samples).

\section{Determination of $\alpha$-glucosidase activity in dried blood spot extracts}

$\alpha$-Glucosidase activities in DBS extracts were determined under the following assay conditions:

1. At pH 7.0 for determination of the neutral $\alpha$-glucosidase activity, a measure of sample integrity

2. At $\mathrm{pH} 3.8$ for the determination of the total acid $\alpha$-glucosidase activity

3. At $\mathrm{pH} 3.8$ in the presence of $4 \mathrm{mmol} / \mathrm{L}$ maltose $(\mathrm{pH} 3.8+$ $\mathrm{M})$ as a measure of the residual acid $\alpha$-glucosidase activity (attributed to GAA) after inhibition of MGA

4. At $\mathrm{pH} 3.8$ in the presence of $8 \mu \mathrm{mol} / \mathrm{L}$ acarbose $(\mathrm{pH} 3.8+$ A) also as a measure of the residual acid $\alpha$-glucosidase activity (attributed to GAA) after inhibition of MGA 
5. At pH 3.8 in the presence of $80 \mu \mathrm{mol} / \mathrm{L}$ acarbose, also as a measure of the residual acid $\alpha$-glucosidase activity (attributed to GAA) after inhibition of MGA

One 3-mm diameter DBS punch was extracted in $360 \mu \mathrm{L}$ $\mathrm{dH}_{2} \mathrm{O}$ by mixing gently for 1 hour at $4^{\circ} \mathrm{C}$ on a rocking platform. The extract was used to perform assays 1 and 2 plus one of the remaining assays 3 to 5 listed below. Enzyme activities were determined in duplicate for each assay condition in a 96-well microtiter plate, and $40 \mu \mathrm{L}$ aliquots of DBS extract were added to the following:

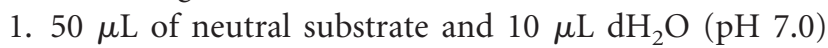
(neutral $\alpha$-glucosidase activity)

2. $50 \mu \mathrm{L}$ of acidic substrate and $10 \mu \mathrm{L} \mathrm{dH}_{2} \mathrm{O}$ (pH 3.8) (total acid $\alpha$-glucosidase activity)

3. $50 \mu \mathrm{L}$ of acidic substrate and $10 \mu \mathrm{L}$ of $40 \mathrm{mM}$ maltose $(\mathrm{pH} 3.8+\mathrm{M})$ (GAA activity)

4. $50 \mu \mathrm{L}$ of acidic substrate and $10 \mu \mathrm{L}$ of $80 \mu \mathrm{M}$ acarbose $(\mathrm{pH} 3.8+\mathrm{A})(\mathrm{GAA}$ activity)

5. $50 \mu \mathrm{L}$ of acidic substrate and $10 \mu \mathrm{L}$ of $800 \mu \mathrm{M}$ acarbose (GAA activity)

The 96-well plates were sealed with an aluminum adhesive sealer and incubated at $37^{\circ} \mathrm{C}$ for 20 hours in a water bath. The remaining DBS extracts were also incubated at $37^{\circ} \mathrm{C}$ for 20 hours, in sealed microfuge tubes protected from light. The plates were centrifuged at $600 \mathrm{~g}$ for 5 minutes to remove condensate from the covers. Enzyme reactions were terminated by the addition of $200 \mu \mathrm{L}$ stop buffer. Blank samples were prepared by the addition of $40 \mu \mathrm{L}$ of the remaining DBS extract to wells containing $50 \mu \mathrm{L}$ of acidic substrate and $10 \mu \mathrm{L} \mathrm{dH_{2 }}$ O that had been incubated in the microtiter plate for 20 hours and $200 \mu \mathrm{L}$ of stop buffer. A calibration curve of 4-MU in $\mathrm{dH}_{2} \mathrm{O}$, ranging from 0 to 312.5 pmol in a total volume of $100 \mu \mathrm{L}$, was prepared in duplicate in the 96-well plate. The fluorescence (relative fluorescence unit) value was determined using a Tecan Spectrafluor fluorometer (Durham, NC) or a SpectraMax M2 (Molecular Devices, Sunnyvale, Calif) with $360 \mathrm{~nm}$ excitation and 465 $\mathrm{nm}$ emission wavelengths ( $35 \mathrm{~nm}$ band width). The mean relative fluorescence unit values for the duplicate assays at $\mathrm{pH}$ 7.0, $\mathrm{pH} 3.8$, pH $3.8+\mathrm{M}$, and $\mathrm{pH} 3.8+$ A were corrected by subtraction of the mean blank relative fluorescence unit value. The absolute amount of 4-MU per well was obtained using the slope of the calibration curve. The enzyme activities were expressed as $\mathrm{pmol} \cdot \mathrm{punch}^{-1} \cdot \mathrm{h}^{-1}$.

\section{Statistical analyses}

Comparison of activities between control and patient groups was performed using the Student $t$ test with GraphPad Prism 3 software (Graphpad Software, San Diego, CA) with Welch's correction for unequal variances where necessary. $P$ values less than .05 were considered to be significant.

\section{RESULTS}

\section{Intraday and interday precision}

Intraday and interday precision were determined using replicate control blood spots. The intraday precision (coefficient of variation) of $\alpha$-glucosidase activity $(n=10)$ was $6.8 \%$ at $\mathrm{pH}$ 3.8 without inhibitor, $7.9 \%$ at $\mathrm{pH} 7,4.7 \%$ at $\mathrm{pH} 3.8+\mathrm{M}$, and $5.5 \%$ at $\mathrm{pH} 3.8+\mathrm{A}$. Interday precision over 20 weeks was $16 \%$ $(n=19)$ at $\mathrm{pH} 3.8$ without inhibitor, $25 \%$ at $\mathrm{pH} 7(n=16)$, $19 \%$ at $\mathrm{pH} 3.8+\mathrm{M}(n=16)$, and $20 \%$ at $\mathrm{pH} 3.8+\mathrm{A}(n=14)$. These results demonstrated the reproducibility of the assay and the stability of activities in blood spots stored at $-20^{\circ} \mathrm{C}$ over 20 weeks. The operator variability was also shown to be reproducible, with less than $15 \%$ difference.

\section{Acid $\alpha$-glucosidase activities in patient, heterozygote, and control blood spots}

Table 1 shows a comparison of $\alpha$-glucosidase activities under four different assay conditions ( $\mathrm{pH} 3.8, \mathrm{pH} 3.8+\mathrm{M}, \mathrm{pH}$ $3.8+\mathrm{A}$, and $\mathrm{pH}$ 7.0) in DBS extracts from patients, heterozygotes, and controls. It also shows the percentage of inhibition of the $\alpha$-glucosidase activities at $\mathrm{pH} 3.8$ by $4 \mathrm{mmol} / \mathrm{L}$ maltose and $8 \mu \mathrm{mol} / \mathrm{L}$ acarbose, and the ratio of neutral $\alpha$-glucosidase activity at pH 7.0 to that at $\mathrm{pH} 3.8+\mathrm{M}$. The $\mathrm{pH} 3.8, \mathrm{pH} 3.8+$ $\mathrm{M}$, and $\mathrm{pH} 7.0$ measurements were obtained simultaneously on the same DBS extracts. The pH $3.8+$ A (acarbose) measurements were obtained in separate experiments. The percentage of inhibition by acarbose was calculated using $\mathrm{pH} 3.8$ activity values obtained during those separate experiments, and the latter are not shown explicitly. The experimental results using $80 \mu \mathrm{mol} / \mathrm{L}$ acarbose have not been included because they show no significant differences, other than greater overall inhibition of enzyme activities at $\mathrm{pH} 3.8$, from those obtained at $8 \mu \mathrm{mol} / \mathrm{L}$ acarbose concentration.

The $\mathrm{pH} 3.8+\mathrm{M}$ and $\mathrm{pH} 3.8+\mathrm{A}$ activities, attributed to acid $\alpha$-glucosidase, were clearly deficient in the infantile-onset Pompe patient group, and there was no overlap with either the control group or the heterozygotes (Table 1 and Fig. 1). In fact, the $\mathrm{pH} 3.8+\mathrm{A}$ and $\mathrm{pH} 3.8+\mathrm{M}$ activities in the patient samples were close to or below the limit of sensitivity of this assay, determined to be $2 \mathrm{pmol} \cdot$ punch $^{-1} \cdot \mathrm{h}^{-1}$, and thus could not be accurately determined (below detection limits). The acarbose and maltose assays were also able to detect an overall reduction in acid $\alpha$-glucosidase activity in the heterozygote group, which had significantly lower mean activities compared with the controls. The mean percentage of inhibition by either inhibitor was significantly greater for the patient samples than controls, suggesting that MGA accounted for a greater proportion of the total $\alpha$-glucosidase activity at $\mathrm{pH} 3.8$ in the patient samples, as would be expected in GAA-deficient individuals.

The neutral $\alpha$-glucosidase activities determined at $\mathrm{pH} 7.0$ were comparable for the control and patient groups. The neutral $\alpha$-glucosidase activity is reportedly less stable than acid $\alpha$-glucosidase activity, and it was proposed that this activity 
Table 1

$\alpha$-Glucosidase activities in dried blood spots

\begin{tabular}{|c|c|c|c|c|c|c|c|}
\hline & pH 3.8 & $\mathrm{pH} 3.8+\mathrm{M}$ & $\mathrm{pH} 3.8+\mathrm{A}$ & pH 7.0 & \multirow{2}{*}{$\begin{array}{l}\text { \% Inhibition } \\
(\mathrm{M})\end{array}$} & \multirow{2}{*}{$\begin{array}{c}\% \text { Inhibition } \\
\text { (A) }\end{array}$} & \multirow[b]{2}{*}{$\mathrm{pH} 7.0 / \mathrm{pH} 3.8+\mathrm{M}$} \\
\hline & \multicolumn{4}{|c|}{$\mathrm{pmol} \cdot \mathrm{punch} \cdot \mathrm{h}$} & & & \\
\hline \multirow[t]{4}{*}{ Controls } & $16 \pm 5.2$ & $11 \pm 3.4$ & $22 \pm 9$ & $45 \pm 17$ & $31 \pm 8.4$ & $49 \pm 9$ & $4.3 \pm 1.3$ \\
\hline & 16 & 11 & 20 & 46 & 31 & 48 & 4.1 \\
\hline & $6.0-28$ & $4.5-20$ & $7.4-51$ & $14-95$ & $8.2-51$ & $30-73$ & $1.4-13.5$ \\
\hline & $(\mathrm{n}=110)$ & $(\mathrm{n}=110)$ & $(\mathrm{n}=150)$ & $(\mathrm{n}=110)$ & $(\mathrm{n}=110)$ & $(\mathrm{n}=150)$ & $(\mathrm{n}=110)$ \\
\hline \multirow[t]{4}{*}{ Heterozygotes } & $7.2 \pm 2.1$ & $4.7 \pm 1.6$ & $4.0 \pm 1.3$ & $35 \pm 13$ & $35 \pm 6.4$ & $49 \pm 10$ & $8.1 \pm 3.8$ \\
\hline & 7.0 & 4.3 & 3.5 & 35 & 35 & 51 & 7.3 \\
\hline & $4.3-12.5$ & $3.0-9.4$ & $2.8-7.2$ & $12-60$ & $21-46$ & $36-64$ & $3.0-16$ \\
\hline & $(\mathrm{n}=16)$ & $(\mathrm{n}=16)$ & $(\mathrm{n}=11)$ & $(\mathrm{n}=16)$ & $(n=16)$ & $(\mathrm{n}=11)$ & $(\mathrm{n}=16)$ \\
\hline \multirow[t]{4}{*}{ Patients } & $3.6 \pm 2.1$ & ${ }^{a} 1.5 \pm 0.8$ & BDL & $43 \pm 20$ & $55 \pm 13$ & $90 \pm 9$ & $32 \pm 14$ \\
\hline & 3.1 & 1.2 & & 44 & 57 & 91 & 31 \\
\hline & $0.73-7.9$ & $0.4-3.1$ & & $15-84$ & $27-75$ & $63-106$ & $13-76$ \\
\hline & $(\mathrm{n}=20)$ & $(\mathrm{n}=20)$ & $(\mathrm{n}=19)$ & $(\mathrm{n}=20)$ & $(\mathrm{n}=20)$ & $(\mathrm{n}=19)$ & $(\mathrm{n}=20)$ \\
\hline
\end{tabular}

$\alpha$-Glucosidase activities at pH 3.8, pH $3.8+$ maltose (M) $4 \mathrm{mmol} / \mathrm{L}, \mathrm{pH} 3.8+$ acarbose (A) $8 \mu \mathrm{mol} / \mathrm{L}$, and pH 7.0 in dried blood spot (DBS) extracts from patients with infantile Pompe disease, heterozygotes, and controls. Relative activities and percentage of inhibition are also shown. Order of data shown: Mean \pm standard deviation, median and range (minimum to maximum).

${ }^{a}$ Some values in the patient group lie below the calculated limit of sensitivity and are therefore of questionable accuracy.

BDL in patients' column at $\mathrm{pH} 3.0+$ acarbose (A) denotes "below detection limits."
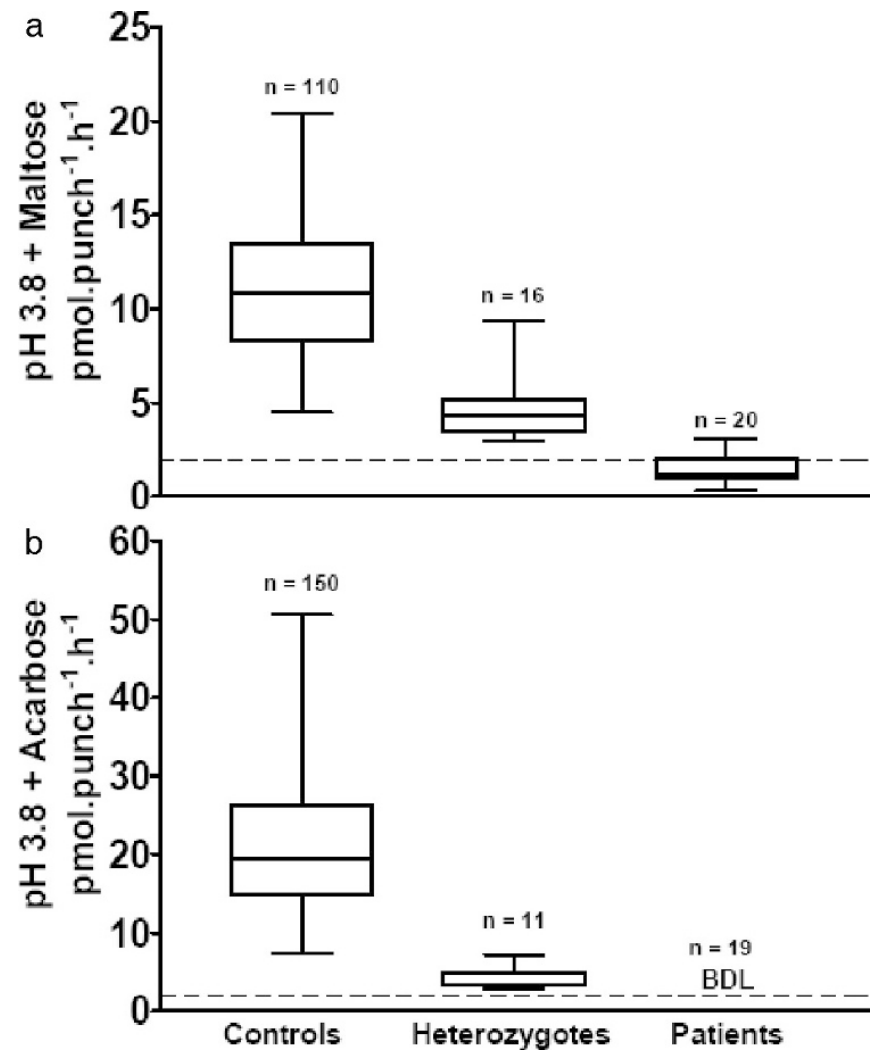

Fig. 1. $\alpha$-Glucosidase activity at $\mathrm{pH} 3.8$ in the presence of (a) $4 \mathrm{mmol} / \mathrm{L}$ maltose or (b) $8 \mu \mathrm{mol} / \mathrm{L}$ acarbose in dried blood spot (DBS) extracts from patients with Pompe disease, heterozygotes, and controls. Median, 25th, and 75th percentiles and minimum to maximum values (box and whiskers). Limit of detection $\left(2 \mathrm{pmol} \cdot \mathrm{punch}^{-1} \cdot \mathrm{h}^{-1}\right)$ (dashed line). The $\mathrm{pH} 3.8+\mathrm{M}$ values for the majority of patients were below the detection limit, and the values shown here for illustrative purposes are therefore not accurate. All of the $\mathrm{pH} 3.8+$ A values in the patient group were below the limit of detection and are denoted as BDL (below detection limit) on the graph. could serve as an internal control for potential loss of activity because of inappropriate sample handling and storage. ${ }^{12}$

\section{DISCUSSION}

We compared assays for the determination of GAA activity in DBS, using 4-MUG as the substrate and maltose or acarbose as inhibitors of MGA. We showed that these assays are reproducible and are able to differentiate patients with proven infantile Pompe disease from healthy controls. Acarbose at 8 $\mu \mathrm{mol} / \mathrm{L}$ concentration was a more potent inhibitor of $\alpha$-glucosidase activity at $\mathrm{pH} 3.8$ than $4 \mathrm{mmol} / \mathrm{L}$ maltose in both control and patient samples and resulted in a higher percentage inhibition of activity at $\mathrm{pH} 3.8$. The greater inhibitory effect of acarbose on the $\alpha$-glucosidase activity at pH 3.8 reflects a more complete inhibition of MGA activity, but may also be the result of partial inhibition of GAA. The specificity of the inhibitory effects of maltose and acarbose under the reaction conditions used in our studies is not known. Although MGA reportedly has a higher affinity to both maltose and acarbose than GAA, ${ }^{1,9,10,13,16}$ both compounds also inhibit purified recombinant rhGAA activity determined using 4-MUG as the substrate (data not shown). One apparent limitation of the DBS assay is that it cannot distinguish the infantile form of Pompe from the later-onset forms. DBSs were collected recently during an international multicenter late-onset Pompe disease observational study, sponsored by Genzyme Corporation (Cambridge, Mass), and analyzed using the protocol described here. The assay is equally sensitive for detecting the late-onset form of the disease, and detailed results from this extensive study will be published separately. In the event of a positive result 
from this assay, we would recommend a second tier of testing using skin or muscle biopsy samples to measure residual GAA activity, which is able to distinguish between early and lateronset forms.

It should be noted that the urine assay for the specific glucose tetrasaccharide $\mathrm{Glc}_{4},{ }^{17}$ which can be performed on a dried urine specimen on filter paper with a similar turnaround time, might also discriminate patients with infantile and late-onset forms of the disease. In the clinical setting, a decision as to whether or not to begin ERT before establishing the definitive diagnosis should be facilitated when both of these test results are available. Furthermore, negative results from both these tests would quickly rule out the diagnosis of Pompe disease and avoid unnecessary invasive procedures.

\section{CONCLUSION}

Thus, GAA determination in DBSs using maltose or acarbose as inhibitors of MGA with 4-MUG as the substrate is a reliable method for the detection of GAA deficiency and is suitable for screening patients at risk for infantile Pompe disease. The convenience of collecting a peripheral blood specimen by heel or finger stick coupled with that of mailing the specimen to a distant reference laboratory, plus the short turnaround time of the assay ( $<48$ hours), makes it an attractive alternative to the more invasive assays currently used. The advent of ERT for Pompe disease makes an early diagnosis of paramount importance, because trials have shown a better response in those patients treated at an earlier age. Another potential application for this bloodspot GAA assay is in newborn screening for Pompe disease.

\section{ACKNOWLEDGMENTS}

PSK, TYC, and DSM have received research/grant support and honoraria from Genzyme Corporation; PSK is a member of the Pompe Disease Registry Advisory Board for Genzyme Corporation. YTC has served as a consultant for Genzyme Corporation. SPY and HZ have been supported through a research grant. The authors thank Dr. Nestor Chamoles (de- ceased), Dr. Gabriela Niizawa, and colleagues for advice and sample exchange.

\section{References}

1. Hirschhorn R, Reuser AJJ. Glycogen storage disease type II: acid $\alpha$-glucosidase (acid maltase) deficiency. In: The Metabolic and Molecular Bases of Inherited Disease. 8th edition. Scriver CR, Beaudet AC, Sly WS, Valle D (eds.). New York: McGraw-Hill, 2000;3389-3420.

2. van den Hout HM, Hop W, van Diggelen, OP, Smeitink JA, et al. The natural course of infantile Pompe's disease: 20 original cases compared with 133 cases from the literature. Pediatrics 2003;112:332-340.

3. Kishnani PS, Hwu P, Mandel H, Nicolino M, et al A retrospective multinational, multicenter study of the natural history of infantile Pompe disease. J Pediatr (in press).

4. Kishnani PS, Nicolino M, Voit T, Rogers RC, et al. Results from a phrase II trial of Chinese hamster ovary cell-derived recombinant human acid alpha-glucosidase in infantile-onset Pompe disease. J Pediatr (in press).

5. Desnick RJ. Enzyme replacement and enhancement therapies for lysosomal diseases. J Inherit Metab Dis 2004;27:385-410.

6. Amalfitano A, Bengur AR, Morse RP, Majure JM, et al. Recombinant human acid alpha-glucosidase enzyme therapy for infantile glycogen storage disease type II: results of a phase I/II clinical trial. Genet Med 2001;3:132-138.

7. Brady RO, Schiffmann R. Enzyme-replacement therapy for metabolic storage disorders. Lancet Neurol 2004;3:752-756.

8. Van den Hout HM, Kamphoven JH, Winkel LP, Arts WF, et al. Long-term intravenous treatment of Pompe disease with recombinant human alpha-glucosidase from milk. Pediatrics 2004;113:e448-457.

9. Jeffrey PL, Brown DH, Brown BI. Studies of lysosomal $\alpha$-glucosidase. II. Kinetics of action of the rat liver enzyme. Biochemistry 1970;9:1416-1422.

10. Matsui H, Saski M, Takemasa E, Kaneta T, et al. Kinetic studies on the substrate specificity and active site of rabbit muscle acid alpha-glucosidase. J Biochem 1984; 96:993-1004.

11. Marsden D, Larson C, Levy HL. Newborn screening for metabolic disorders. J Pediatr 2006 (in press).

12. Umapathysivam K, Hopwood JJ, Meikle PJ. Determination of acid $\alpha$-glucosidase activity in blood spots as a diagnostic test for Pompe disease. Clin Chem 2001;47: $378-383$.

13. Chamoles AN, Niizawa G, Blanco M, Gaggioli D, et al. Glycogen storage disease type II: enzymatic screening in dried blood spots on filter paper. Clin Chim Acta 2004; 347:97-102.

14. Li Y, Scott CR, Chamoles NA, Ghavami A, et al. Direct multiplex assay of lysosomal enzymes in dried blood spots for newborn screening. Clin Chem 2004;50:17851796.

15. Dreyfus JC, Poenaru L. Alpha-glucosidases in white blood cells with reference to the detection of acid alpha-1, 4-glucosidase deficiency. Biochem Biophys Res Comm 1978;85:615-622.

16. Shin YS, Endres W, Unterreithmeier J, Rieth M, et al. Diagnosis of Pompe's disease using leukocyte preparations. Kinetic and immunological studies of 1, 4- $\alpha$-glucosidase in human fetal and adult tissues and cultured cells. Clin Chim Acta 1985;148: 9-19.

17. An Y, Young SP, Kishnani PS, Millington DS, et al. Glucose tetrasaccharide as a biomarker for monitoring the therapeutic response to enzyme replacement therapy for Pompe disease. Mol Genet Metab 2005;85:247-254. 